\title{
Lassa and Crimean-Congo Hemorrhagic Fever Viruses, Mali
}

\section{Jan Baumann, ${ }^{1}$ Mandy Knüpfer, ${ }^{1}$ Judicael Ouedraogo, Brehima Y. Traoré, Asli Heitzer, Bourama Kané, Belco Maiga, Mariam Sylla, Bouréma Kouriba, ${ }^{2}$ Roman Wölfel ${ }^{2}$}

We report detection of Lassa virus and Crimean-Congo hemorrhagic fever virus infections in the area of Bamako, the capital of Mali. Our investigation found 2 cases of infection with each of these viruses. These results show the potential for both of these viruses to be endemic to Mali.

$\mathrm{N}$ umerous viral hemorrhagic fevers are endemic to countries in Africa. Despite the underlying pathogens originating from diverse virus families, clinical features of hemorrhagic fevers are similar, including fever, malaise, abdominal pain, vomiting, headache, and myalgia (1). These nonspecific symptoms and their similarity to other infectious diseases common in West Africa, such as malaria, complicate the differential diagnosis. In regions where surveillance data are limited and healthcare workers are less aware of viral hemorrhagic diseases, the possibility for misdiagnosis is high.

Lassa virus (LASV; species Lassa mammarenavirus, genus Arenaviridae) is the causative agent of Lassa fever. The multimammate rat, Mastomys spp., is the natural host of LASV and sheds the virus in urine and droppings. Transmission of LASV to humans usually occurs through contact with the excreta of infected rodents or with body fluids from persons with symptomatic illness.

Lassa fever is known to be endemic in parts of West Africa; most cases are reported from Guinea, Liberia, Sierra Leone, and Nigeria. LASV species in these geographic regions are related genetically, suggesting an ongoing exchange between LASV-endemic regions (2). People living in rural areas of West Africa are most at risk for Lassa fever. In recent years, an increasing trend in the number of Lassa fever cases has been observed in countries of West Africa. Annually, $\approx 300,000$ persons are infected with

Author affiliations: Bundeswehr Institute of Microbiology,

Munich, Germany (J. Baumann, M. Knüpfer, A. Heitzer, R. Wölfel); Centre d'Infectiologie Charles Mérieux du Mali, Bamako, Mali

(J. Ouedraogo, B.Y. Traoré, B. Kouriba); Hôpital du Mali, Bamako

(B. Kané); Centre Hospitalier Universitaire Hospital Gabriel Touré, Bamako (B. Maiga, M. Sylla)

DOI: https://doi.org/10.3201/eid2505.181047
LASV in virus-endemic areas, and $\approx 5,000$ die. Because LASV infections can be asymptomatic, case numbers likely are underestimated (3). Although some reports describe serologic evidence that LASV is endemic to Mali $(4,5)$, few surveillance studies have been conducted. One such study identified a distinct LASV clade in rodents $280 \mathrm{~km}$ south of Bamako, the capital of Mali (6). In addition, a young man traveling in the border region of Mali and Burkina Faso died from an acute LASV infection in 2009 after returning to the United Kingdom (7).

Another prominent pathogen causing hemorrhagic fever, Crimean-Congo hemorrhagic fever virus (CCHFV; family Nairoviridae, genus Orthonairovirus), is endemic to many regions, including Eurasia, Central America, and parts of Europe and Africa. To date, reports of acute $\mathrm{CCH}$ FV infections in West Africa are limited to Senegal (8) and Mauritania (9). Nevertheless, recent studies confirmed the incidence of CCHFV in Hyalomma spp. ticks collected from domestic cattle in southern Mali (10). In addition, serologic studies show evidence for human contact with CCHFV (11). However, no human cases of acute infection with CCHFV have been identified in Mali. We describe 2 cases of LASV infection and 2 cases of CCHFV infection detected in hospitalized pediatric patients in Bamako.

\section{The Study}

During April 2016-May 2017, we screened malaria-negative blood samples collected at the pediatric department of the University Hospital Gabriel Touré and the pediatric ward of Hôpital du Mali, both located in Bamako. We included febrile patients 3 months to 14 years of age in the study. We obtained ethics approval from the Research Ethics Institutional Review Board, University of Bamako, Mali (no. 2016/01/CE/FMPOS).

We screened 489 samples for various bacterial and viral pathogens, including LASV and CCHFV. We extracted total nucleic acid using the QIAamp viral RNA kit (QIAGEN, https://www.qiagen.com) and amplified viral RNA by using LASV reverse transcription PCR (12) and CCHFV reverse transcription quantitative PCR (13) protocols.

We detected LASV RNA in blood samples from 2 patients, a 5-year-old boy and a 13-year-old girl. Both children were treated for episodes of high fever during

${ }^{1}$ These authors contributed equally to this article.

${ }^{2}$ These authors were co-principal investigators. 
September-October 2016 at the Hôpital du Mali. The Centre d'Infectiologie Charles Mérieux du Mali in Bamako performed conventional reverse transcription PCR and gel electrophoresis on the LASV. Isolated DNA fragments were shipped to the Bundeswehr Institute of Microbiology (Munich, Germany) for further investigation.

Diagnostic amplicons of the LASV small (S) RNA segment, $278 \mathrm{nt}$ from the boy and $276 \mathrm{nt}$ from the girl, were sequenced by Sanger sequencing (GenBank accession nos. MH473586-7). Sequence analysis of the viral S segment showed that 1 patient was infected by a LASV strain that clusters genetically with viruses belonging to lineage IV (Figure 1). Because lineage IV strains previously were not reported to circulate in wildlife in Mali, we suspect this virus reached the country through regional migratory activity of wildlife. Nevertheless, epidemiologic data about LASV in Mali are limited, and frequent exchange between the LASV lineages in West Africa is possible.

The second identified Lassa fever case was caused by a LASV strain belonging to the Mano River clade with $91 \%$ similarity to Lassa Soromba R (GenBank accession no. KF478765) (Figure 1). This virus was first isolated in 2010 from rodents near the village Soromba at the southern tip of Mali (6). Additional laboratory characterization at that time revealed a relatively mild pathogenicity in macaques (14). However, Lassa

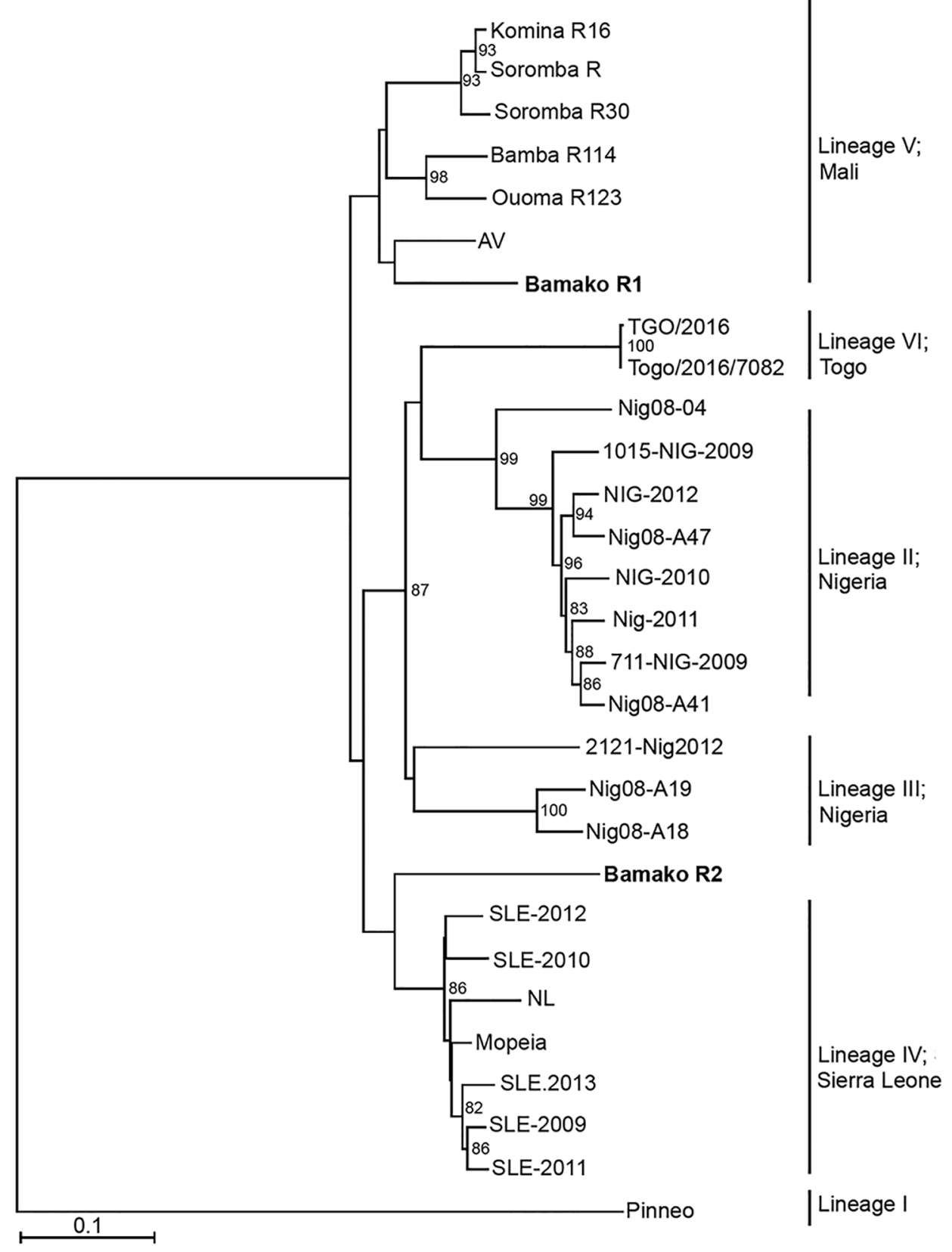

Figure 1. Phylogenetic analysis of representative Lassa virus (LASV) isolates identified in Mali in 2016 (bold) and reference isolates. The tree was constructed by using full-length sequences of the small RNA segment and the neighbor-joining method with bootstrapping to 10,000 iterations. Partial sequences were compared by using the pairwise deletion method. The tree is drawn to scale. Evolutionary analyses were conducted in MEGA7 (https:// www.megasoftware.net). Scale bar indicates nucleotide substitutions per site. 
Soromba $\mathrm{R}$ is closely related to the AV strain (GenBank accession no. FR832711) that caused a fatal infection in a young man who returned to Germany after traveling to Ghana, Côte d'Ivoire, and Burkina Faso in 2000 (15) and is related to a strain from a patient in the United Kingdom who likely was infected in the border region between Mali and Burkina Faso in 2009 (7). Because the case we identified originated in a district of Bamako, we believe LASV could be more widely distributed in southern Mali than previously believed.

We also detected CCHFV, which previously was not known to circulate in the population of Mali. Using reverse

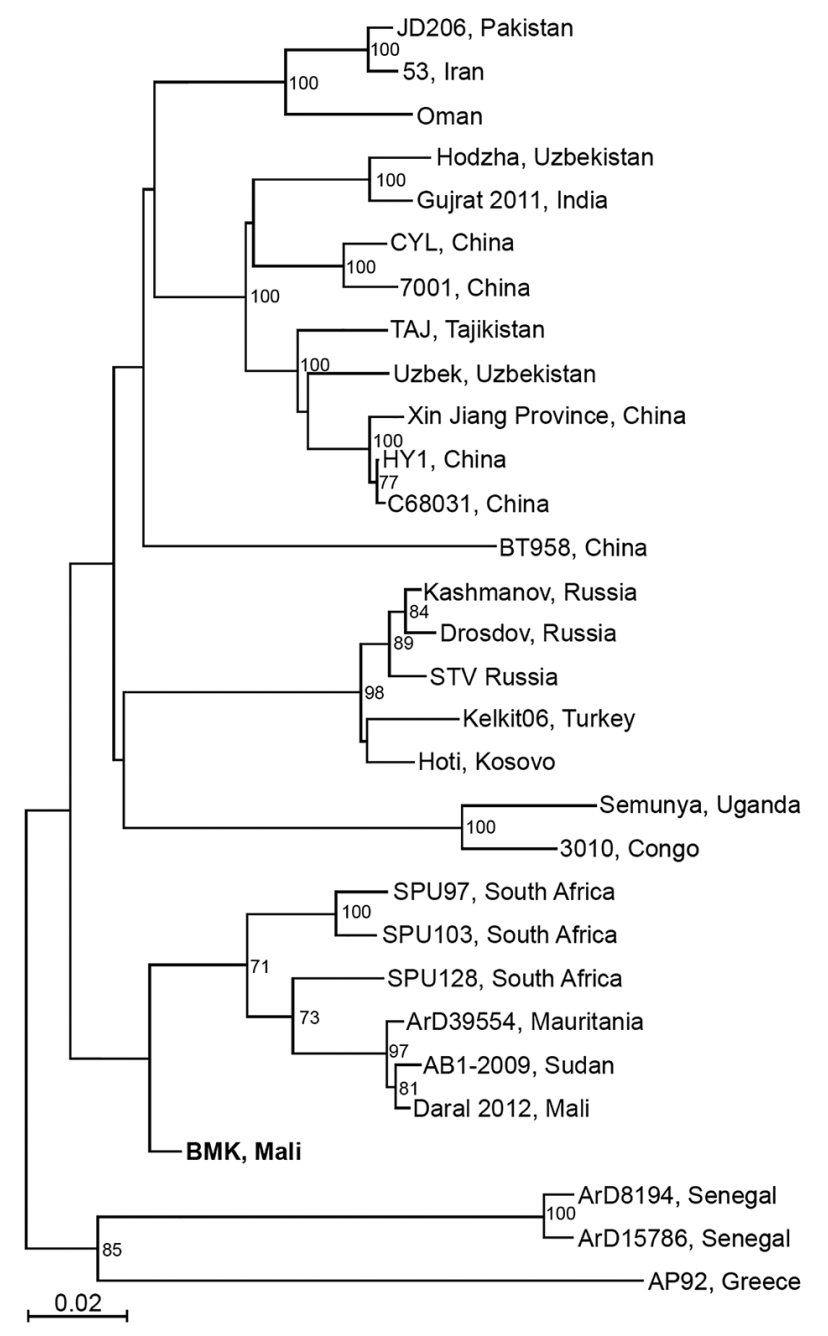

Figure 2. Phylogenetic analysis of representative Crimean-Congo hemorrhagic fever virus (CCHFV) isolates identified in Mali in 2017 (bold) and reference isolates. The tree was constructed by using full-length sequences of the small RNA segment and the neighbor-joining method with bootstrapping to 10,000 iterations. Partial sequences were compared by using the pairwise deletion method. The tree is drawn to scale. Evolutionary analyses were constructed in MEGA7 (https://www.megasoftware.net). Scale bar indicates nucleotide substitutions per site. transcription quantitative PCR, we detected acute CCHFV infection in 2 patients hospitalized at Hospital Gabriel Touré in April 2017, a 1-year-old boy (cycle threshold 32.74) and a 2-year-old boy (cycle threshold 36.95). We obtained sequence data from the viral $\mathrm{S}$ segment for the 1-year-old boy. Phylogenetic analysis showed that this virus is related to CCHFV strain ArD39554 from Mauritania and CCHFV sequence (GenBank accession no. KF793333) recently detected in ticks collected only $25 \mathrm{~km}$ from Bamako (10) (Figure 2). We were unable to extract sufficient genomic material to perform sequencing on samples from the second case-patient.

\section{Conclusions}

In summary, our study detected 2 cases of infection with LASV in Bamako, Mali, indicating a broader distribution of LASV in Mali than previously known. This finding raises serious public health concerns for future LASV infection in cities in Mali. We also identified 2 human cases of infection with CCHFV in Mali, suggesting an extended CCHFV-endemic region in Africa. Our results underline the need for LASV and CCHFV surveillance programs in sub-Saharan regions of Mali, Burkina Faso, and Niger, which have similar ecology.

\section{Acknowledgments}

We thank the patients and their parents for participating in this study, as well as Erna Fleischmann and Kathrin Baumann for skillful technical assistance, and multiple host-country investigators for their hard work and dedication.

This study was funded through the German Biosecurity Program under grant no. OR12-01-370.43-BIOS-IMB-MLI and by the Medical Biodefense Research Program of the German Bundeswehr Medical Service.

\section{About the Author}

Dr. Baumann is a research scientist at the Bundeswehr Institute of Microbiology. He is interested in improving viral disease diagnostic capacities in the G5-Sahel region and his research interest focuses on the epidemiology of hemorrhagic fever viruses.

\section{References}

1. World Health Organization. Lassa fever. March 2016 [cited 5 Mar 2018]. http://www.who.int/mediacentre/factsheets/fs179

2. Sogoba N, Feldmann H, Safronetz D. Lassa fever in West Africa: evidence for an expanded region of endemicity. Zoonoses Public Health. 2012;59(Suppl 2):43-7. http://dx.doi.org/10.1111/ j.1863-2378.2012.01469.x

3. McCormick JB, Fisher-Hoch SP. Lassa fever. Curr Top Microbiol Immunol. 2002;262:75-109. http://dx.doi.org/10.1007/ 978-3-642-56029-3_4

4. Richmond JK, Baglole DJ. Lassa fever: epidemiology, clinical features, and social consequences. BMJ. 2003;327:1271-5. http://dx.doi.org/10.1136/bmj.327.7426.1271 
5. Sogoba N, Rosenke K, Adjemian J, Diawara SI, Maiga O, Keita M, et al. Lassa virus seroprevalence in Sibirilia Commune, Bougouni District, southern Mali. Emerg Infect Dis. 2016; 22:657-63. http://dx.doi.org/10.3201/eid2204.151814

6. Safronetz D, Lopez JE, Sogoba N, Traoré' SF, Raffel SJ, Fischer ER, et al. Detection of Lassa virus, Mali. Emerg Infect Dis. 2010;16:1123-6. http://dx.doi.org/10.3201/eid1607.100146

7. Atkin S, Anaraki S, Gothard P, Walsh A, Brown D, Gopal R, et al. The first case of Lassa fever imported from Mali to the United Kingdom, February 2009. Euro Surveill. 2009;14:1-3. https://doi.org/10.2807/ese.14.10.19145-en

8. Tall A, Sall AA, Faye O, Diatta B, Sylla R, Faye J, et al. Two cases of Crimean-Congo hemorrhagic fever (CCHF) in two tourists in Senegal in 2004 [in French]. Bull Soc Pathol Exot. 2009;102:159-61.

9. Nabeth P, Cheikh DO, Lo B, Faye O, Vall IO, Niang M, et al. Crimean-Congo hemorrhagic fever, Mauritania. Emerg Infect Dis. 2004;10:2143-9. http://dx.doi.org/10.3201/eid1012.040535

10. Zivcec M, Maïga O, Kelly A, Feldmann F, Sogoba N, Schwan TG, et al. Unique strain of Crimean-Congo hemorrhagic fever virus, Mali. Emerg Infect Dis. 2014;20:911-3. http://dx.doi.org/10.3201/ eid2005.131641

11. Safronetz D, Sacko M, Sogoba N, Rosenke K, Martellaro C, Traoré S, et al. Vectorborne infections, Mali. Emerg Infect Dis. 2016;22:340-2. http://dx.doi.org/10.3201/eid2202.150688
12. Olschläger S, Lelke M, Emmerich P, Panning M, Drosten C, Hass M, et al. Improved detection of Lassa virus by reverse transcription-PCR targeting the $5^{\prime}$ region of S RNA. J Clin Microbiol. 2010;48:2009-13. http://dx.doi.org/10.1128/ JCM.02351-09

13. Atkinson B, Chamberlain J, Logue CH, Cook N, Bruce C, Dowall SD, et al. Development of a real-time RT-PCR assay for the detection of Crimean-Congo hemorrhagic fever virus. Vector Borne Zoonotic Dis. 2012;12:786-93. http://dx.doi.org/10.1089/ vbz.2011.0770

14. Safronetz D, Strong JE, Feldmann F, Haddock E, Sogoba N, Brining D, et al. A recently isolated Lassa virus from Mali demonstrates atypical clinical disease manifestations and decreased virulence in cynomolgus macaques. J Infect Dis. 2013;207:131627. http://dx.doi.org/10.1093/infdis/jit004

15. Günther S, Emmerich P, Laue T, Kühle O, Asper M, Jung A, et al. Imported Lassa fever in Germany: molecular characterization of a new Lassa virus strain. Emerg Infect Dis. 2000;6:466-76. http://dx.doi.org/10.3201/eid0605.000504

\footnotetext{
Address for correspondence: Roman Wölfel, Bundeswehr Institute of Microbiology, Neuherbergstrasse 11, 80937 Munich, Germany; email: romanwoelfel@instmikrobiobw.de
}

\section{EID Podcast: A Worm's Eye View}

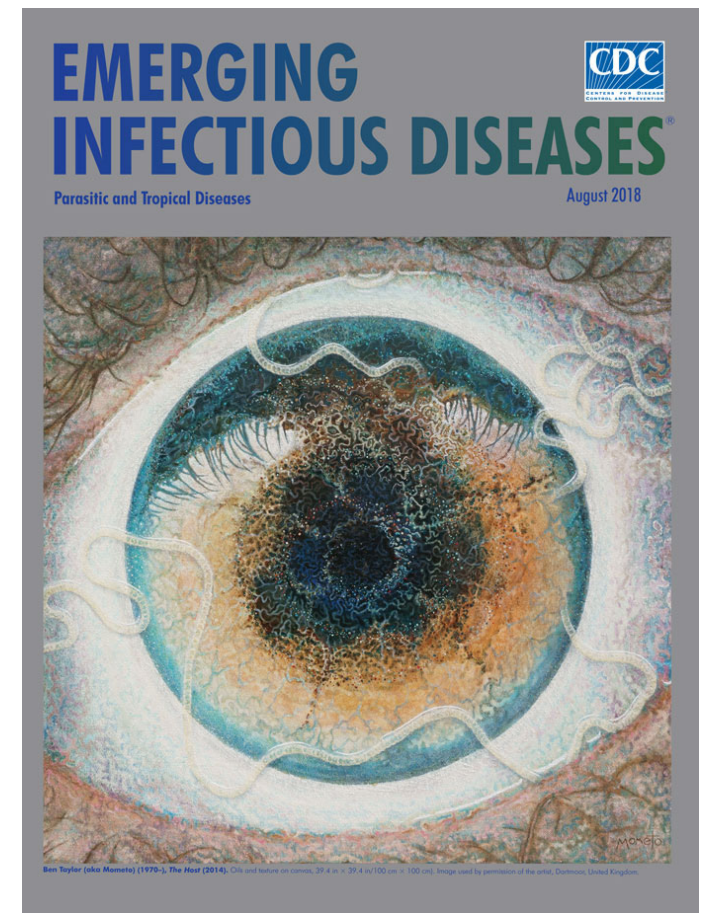

Seeing a several-centimeters-long worm traversing the conjunctiva of an eye is often the moment when many people realize they are infected with Loa loa, commonly called the African eyeworm, a parasitic nematode that migrates throughout the subcutaneous and connective tissues of infected persons. Infection with this worm is called loiasis and is typically diagnosed either by the worm's appearance in the eye or by a history of localized Calabar swellings, named for the coastal Nigerian town where that symptom was initially observed among infected persons. Endemic to a large region of the western and central African rainforests, the Loa loa microfilariae are passed to humans primarily from bites by flies from two species of the genus Chrysops, C. silacea and C. dimidiate. The more than 29 million people who live in affected areas of Central and West Africa are potentially at risk of loiasis.

Ben Taylor, cover artist for the August 2018 issue of EID, discusses how his personal experience with the Loa loa parasite influenced this painting.

\section{Visit our website to listen: https: / /tools.cdc.gov/ EMEREING medialibrary/index.aspx\#/ media/id/392605 INFECTIOUS DISEASES}

